\title{
Quantification of antimicrobial consumption in adult cattle on dairy herds in Flanders, Belgium, and associations with udder health, milk quality, and production performance
}

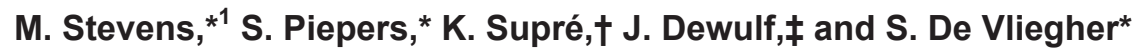 \\ *M-team and Mastitis and Milk Quality Research Unit, Department of Reproduction, Obstetrics and Herd Health, Faculty of Veterinary Medicine, \\ Ghent University, 9820 Merelbeke, Belgium \\ †Milk Control Centre Flanders, 2500 Lier, Belgium \\ †Veterinary Epidemiology Unit, Department of Reproduction, Obstetrics and Herd Health, Faculty of Veterinary Medicine, Ghent University, \\ 9820 Merelbeke, Belgium
}

\begin{abstract}
The main objective of this study was to quantify the (compound-specific) antimicrobial consumption (AMC) in adult cattle in a convenience sample of Flemish dairy herds. Antimicrobial consumption data were obtained between 2012 and 2013 by "garbage can audits" and expressed as antimicrobial treatment incidence (ATI), with the unit of the ATI being the number of defined daily doses animal (DDDA) used per 1,000 cow-days. Herds were stratified by DDDA into low-, medium-, and high-consuming herds to study the AMC per route of administration, and associations with parameters reflecting udder health, milk quality, and production performances were examined. The average ATI in adult dairy cattle for all compounds was 20.78 DDDA (per 1,000 cow-days). Large variation existed between herds (ranging from 8.68 to 41.62 DDDA). Fourth-generation cephalosporins were used most (4.99 DDDA), followed by penicillins (3.70 DDDA) and third-generation cephalosporins (2.95 DDDA). The average ATI of the critically important antimicrobials for human health (i.e., third- and fourth-generation cephalosporins and fluoroquinolones according to the World Organisation for Animal Health classification) was somewhat lower than the average ATI of the other antimicrobials (8.59 and 12.18 DDDA, respectively). The average ATI for intramammary treatment of (sub)clinical mastitis, for dry-cow therapy, and for systemically administered antimicrobials was 6.30,6.89, and 7.44 DDDA, respectively. In low-consuming herds, most antimicrobials were being used for dry-cow therapy, whereas in highconsuming herds, most antimicrobials were being used as injectable or intramammary mastitis therapy. The incidence rate of treated mastitis was positively associated with ATI. Herds that applied blanket dry-cow
\end{abstract}

Received August 3, 2015.

Accepted November 15, 2015.

${ }^{1}$ Corresponding author: Marina.Stevens@UGent.be therapy tended to have a higher ATI than herds in which cows were selectively dried off with long-acting antimicrobials. The ATI decreased with an increasing prevalence of primiparous cows.

Key words: antimicrobial consumption, dairy herd, milk quality, production, udder health

\section{INTRODUCTION}

Approximately $50 \%$ of all antibacterial agents used annually in the European Union are administered to animals (van den Bogaard and Stobberingh, 2000). Antimicrobials have important benefits for animal health and production performances. Still, injudicious antimicrobial consumption (AMC) in food-producing animals is considered to contribute to the increase of antimicrobial resistance in bacterial populations with potentially serious implications for both animal and public health (Marshall and Levy, 2011; Oliver and Murinda, 2012). The more a specific antimicrobial is used, the more likely it is that resistant populations will develop among both pathogens and commensal bacteria of an increasing number of animals in the exposed population (Schwarz et al., 2001; Phillips et al., 2004; Chantziaras et al., 2014).

To safeguard the effectiveness of existing and novel antimicrobials, there is increasing global pressure to develop strategies in both human and veterinary medicine to slow the emerging resistance in bacteria by selection pressure (Morley et al., 2005). In particular, the emergence of resistance to antimicrobials classified by the World Health Organization (WHO) as critically important for human health, primarily fluoroquinolones and third- and fourth-generation cephalosporins, is a point of major concern. In response, international organizations such as the WHO and the World Organisation for Animal Health (Office International des Épizooties, OIE; Paris, France), as well as several national organizations worldwide (Wray and Gnanou, 2000), are vigorously engaged in developing programs intended to 
monitor the emergence of antimicrobial resistance and to decrease AMC (DeVincent and Viola, 2006). Over the last couple of years, the AMC in fattening pigs, poultry, and veal calves has been extensively studied worldwide (Dunlop et al., 1998; Vieira et al., 2011; Bos et al., 2013), including in Belgium (Callens et al., 2012; Pardon et al., 2012; Persoons et al., 2012). Studies on AMC on dairy herds have been conducted in several countries (Meek et al., 1986; Sawant et al., 2005; Pol and Ruegg, 2007; Saini et al., 2012; Redding et al., 2014), but until now, data about AMC on dairy farms in Belgium have been unavailable. A thorough knowledge of the AMC and its related factors is, however, a prerequisite when intending to control the emergence of antimicrobial resistance.

The main objective of this study was to quantify (compound-specific) AMC on a convenience sample of Flemish dairy herds. We determined for what indications antimicrobials were being used and how they were administered in particular. In addition, we examined potential associations between AMC and parameters related to the study design and study implementation and parameters reflecting udder health, milk quality, and production performance.

\section{MATERIALS AND METHODS}

\section{Herds}

Data collected for this study originated from 57 Flemish dairy herds selected based on their willingness to participate (convenience sample). Data collection was performed between January 2012 and February 28, 2013. Herd inclusion criteria were (1) participation in the DHI program in Flanders on an annual basis with an interval of 4 to 6 wk between 2 test-days, and (2) record keeping of all treatments in adult cattle (date of occurrence, identification number of animal, treatment protocol applied). In total, 71 farmers volunteered, but only 61 herds met the inclusion criteria. Of these herds, 3 were eventually excluded because of imprecise treatment registration data and carelessness of collection of empty antimicrobial recipients. One herd dropped out because participation in the DHI program ended during the data collection period. Livestock-associated data were obtained from surveys acquired by a single individual between January 2012 and March 2013.

At the beginning of the project, all participating farmers and their herd veterinarians were invited to attend an interactive meeting where more information was given about the rationale of the study and the study design.

To evaluate the representativeness of the 57 conveniently selected participating herds regarding udder health and milk quality, 275 nonparticipating herds were randomly selected from the database of Milk Control Center Flanders, comprising all Flemish dairy producers $(\mathrm{n}=5,261)$, using the Excel RAND function (Excel 2010; Microsoft Corp., Redmond, WA). Data on bulk milk SCC, total bacterial count, and coliform count of $52,17,27,77$, and 100 herds from the provinces Antwerp, Flemish Brabant, Limburg, East Flanders, and West Flanders, respectively, were collected and compared with those of the 57 conveniently selected herds. The number of herds per province matched the distribution of dairy herds over the 5 Flemish provinces $(19,6,10,28$, and $37 \%$, respectively; Federal Public Service Economy, Small and Medium Enterprises, SelfEmployed, and Energy, 2011).

\section{Udder Health}

Individual $\boldsymbol{S C C}$. Individual SCC data were available from all cows through DHI records with an interval of 4 to 6 wk between 2 test-days (CRV, Arnhem, the Netherlands). Individual SCC was quantified by electronic counting (Fossomatic 5000, Foss Electric, Hillerød, Denmark). Based on the individual SCC data, the average monthly herd-level prevalence of chronic infections, new infections, and high fresh cows were calculated (Table 1).

Incidence Rate of Treated Mastitis. Treatment records for all mastitis cases, both clinical and subclinical, were recorded by farmers, either on paper or in an online registration software program (Veemanager, CRV, Arnhem, the Netherlands; Uniform Agri, Taunton, UK; Cercosoft, Oudenaarde, Belgium; Lely, Maassluis, the Netherlands; Delaval, Tumba, Sweden; Fullwood, Shropshire, UK). Date of occurrence, cow identification, treatment reason and duration, interval between subsequent administrations, and the dose of the used antimicrobial were preferably recorded. The herd-level incidence rate of treated mastitis (IRTM) was calculated by dividing the number of treated cows by the cow-days at risk and expressed as treated cases per 10,000 cow-days at risk. Treatments of the same cow within 2 wk from a previous case were not considered new cases and therefore excluded from the analysis (Verbeke et al., 2014). The at-risk period for a cow started at the beginning of the study or at the date of first calving and ended at the end of the study or at the culling date minus $14 \mathrm{~d}$ after each case of treatment. Additional cow-level records [calving date(s) and culling date] were retrieved from DHI records.

\section{Milk Quality}

Bulk Milk SCC. Bulk milk SCC (BMSCC) records measured at approximately 1 -wk intervals were 
available from the Milk Control Center Flanders (Lier, Belgium) that executes the (regulatory) herd screening program in Flanders. The BMSCC was examined on unpasteurized bulk milk samples collected in $50-\mathrm{mL}$ sterile tubes by the automatic sampling system of the milk tanker. The samples were kept cool $\left( \pm 4^{\circ} \mathrm{C}\right)$ until arrival at the laboratory. All analyses were performed within $48 \mathrm{~h}$ after collection at the herd. The milk samples were vortexed before the start of the analyses. Bulk milk SCC was quantified by electronic counting (Fossomatic 5000, Foss Electric, Hillerød, Denmark). First, the monthly geometric mean herd-level BMSCC was calculated based on the 1 -wk measurements. Subsequently, the average of the herd-level geometric mean BMSCC was calculated.

Bacterial Count and Coliform Count. Both the bulk milk bacterial count (BC) and coliform count (CC) records measured at 2-wk intervals during the data collection period were retrieved from Milk Control Center Flanders. All parameters were examined on unpasteurized bulk milk samples collected in 50$\mathrm{mL}$ sterile tubes by the automatic sampling system of the milk tanker. The samples were kept cooled $\left( \pm 4^{\circ} \mathrm{C}\right)$ until arrival at the laboratory. All analyses were performed within $36 \mathrm{~h}$ after collection at the herd. For BC, undiluted milk samples were used and automatically analyzed by means of a BactoScan FC (Foss Electric). Bacterial counts were expressed as the number of individual bacterial counts per $\mathrm{mL}(\mathbf{I B C} / \mathrm{mL})$ of milk. For $\mathrm{CC}$, milk samples were first diluted using tryptone salt broth at 1:10. One milliliter of diluted milk was plated on 3M Petrifilm CC plates (3M, Minneapolis, MN) and incubated at $30^{\circ} \mathrm{C}$ for $24 \mathrm{~h}$. Colony-forming units were counted electronically using an automated colony counter (protoCOL, Synbiosis, Cambridge, UK). Coliform counts were expressed as colony-forming units per milliliter of milk. Per month, a geometric mean BC and $\mathrm{CC}$ was calculated based on the last 4 recordings (last 2 mo). A $\log _{10}$-transformation of the geometric mean $\mathrm{BC}$ and $\mathrm{CC}$ was performed to normalize the data before statistical analyses. Determination of the number of coliforms is not compulsory in Flanders, although is requested by most milk processors. Coliform count was determined for 54 herds (95\%) during the data collection period. The average geometric mean herd-level BC and $\mathrm{CC}$ were calculated in a similar way as the average geometric mean herd-level BMSCC.

\section{Herd-Level Production Performance}

305-d Milk Production. The average 305-d milk production ( $\mathrm{kg}$ of milk) was defined as the cumulative production over the first $305 \mathrm{~d}$ of lactation and was available through the DHI data. Per herd, the mean of the average herd-level 305-d milk production was calculated.

Culling Rate. The culling rate was calculated by dividing the number of culled cows by the cow-days at risk and is expressed as the number of cows culled per 10,000 cow-days at risk. The at-risk period for a cow started at the beginning of the project or at the date of first calving and ended at the end of the data collection period or at the culling date.

Calving Rate of Multiparous Cows. This parameter was used as a proxy for the number of cows dried off during the observation period as no other data were available. The calving rate was calculated by dividing the number of calved multiparous cows by the cow-days at risk and is expressed as number of calved multiparous cows per 10,000 cow-days at risk. The at-risk period for multiparous cows started at the beginning of the project and ended at the calving date during the data collection period or at the end of the data collection period.

Prevalence of Primiparous Cows. The prevalence of primiparous cows was calculated by dividing

Table 1. Overview of the definitions for chronic and new IMI and prevalence of high fresh cows

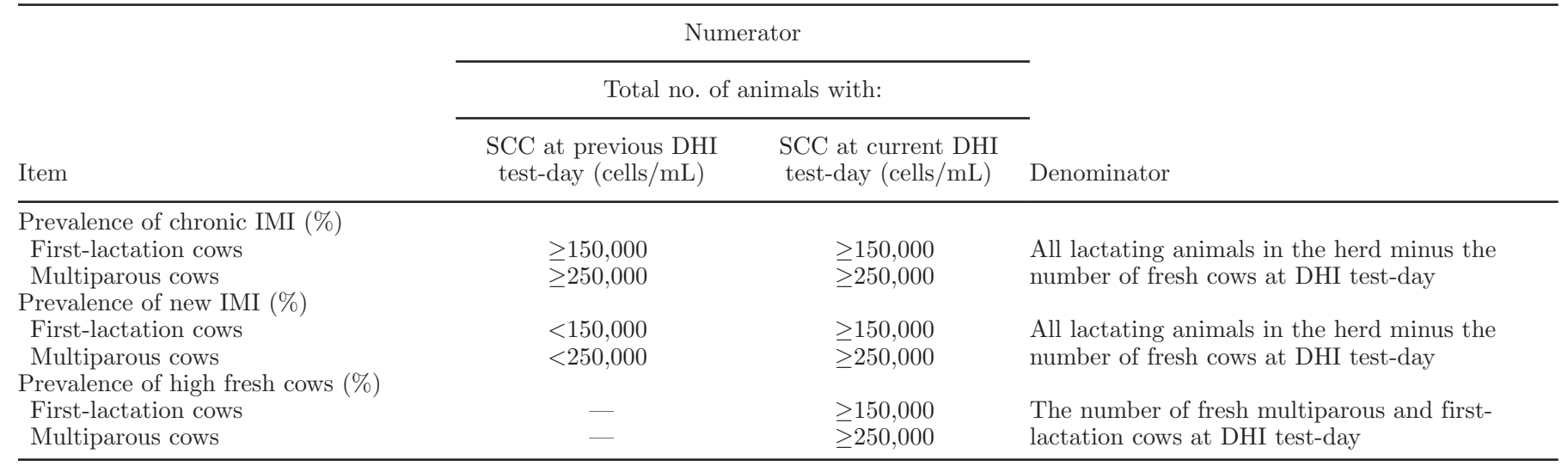


the number of calved primiparous cows during the trial by the total number of cows that calved during the data collection period, multiplied by 100 .

\section{Antimicrobial Consumption Data}

Data Collection. The herds were visited a first time between January 2012 and September 2012. During this first herd visit, "garbage cans" were provided (Dunlop et al., 1998; Carson et al., 2008; Saini et al., 2012). The garbage cans were 51-L receptacles with an open top. Farmers were asked to collect all empty drug vials and tubes used to treat adult dairy cattle (i.e., from the first calving). Antimicrobials used by herd veterinarians or administered to young stock or beef cattle (or both) were not permitted in the garbage can. As a check, farmers were asked if empty packages of antimicrobials administered for young stock or by veterinarians were collected in the garbage cans. On 19 of 56 herds that replied, empty packages of antimicrobials administered to young stock or used by veterinarians were also collected in the garbage can. Products exclusively licensed for young stock and that were, based on the farmer's information, not administered to adult cows (Nuflor, florfenicol, MSD Animal Health, Beaucouzé, France; Resflor, florfenicol and flunixine, MSD Animal Health, Unterschleißheim, Germany; Gabbrovet, paromomycin sulfate, Ceva Santé Animale, Cavriago, Italy) were excluded when calculating the ATI. Farmers scored the reliability of their garbage can collection system as 4.48 on average on a scale from 1 (not reliable) to 5 (very reliable). Because farmers were not always aware of the difference between antimicrobials and, for example, nonsteroidal antiinflammatory drugs or anthelmintics, they were instructed to gather all empty drug receptacles of drugs that they administered themselves in adult dairy cattle into the garbage can (Redding et al., 2014). Broken bottles were collected as well. The garbage cans were positioned at the most convenient spot (e.g., near the drug storage area, in the milking parlor) and were collected twice (August 31, 2012, and February 28, 2013) for processing by the first author. Product name, volume, and number of receptacles were registered using a datasheet that included herd identification number and starting and end date of collection for that particular herd.

Defined Daily Dose Animal. Antimicrobial consumption data were quantified in units of defined daily doses animal (DDDA). One DDDA (mg/cow-day) was defined as the average daily on-label dosage multiplied by the approximate weight of an adult dairy cow (BW $=600 \mathrm{~kg}$; Jensen et al., 2004) and was based on the summary of product characteristics included in the Belgian compendium of veterinary products (BCFI
Vet, 2012). When a range of doses was possible, the average dose was used, as proposed by Postma et al. (2015). When the dose differed among different indications, the most frequent indication or the one for adult dairy cattle was chosen. For combination products, the weights of active ingredients of the constituents were summarized to determine the total weight of active ingredients in the combination compound. Also, 1,000 IU of benzyl penicillin $\mathrm{G}$ procaine equaled $0.99 \mathrm{mg}$. The total dose of long-acting antimicrobials was converted into the number of daily doses according to the duration of action claimed by the manufacturer (Postma et al., 2015). One dry-cow injector was assumed to be 1 DDDA (Scherpenzeel et al., 2014). As a result, a cow that is dried off (receiving 4 dry-cow injectors) was counted for 4 treatment days.

Antimicrobial Treatment Incidence. Antimicrobial consumption at the herd level was expressed by the antimicrobial treatment incidence (ATI; Grave et al., 1999; Timmerman et al., 2006; Pardon et al., 2012). Therefore, the total amount of active substances used in the herd during the study was divided by the DDDA multiplied by the number of herd-level cow-days during the data collection period. The total amount of active substances $(\mathrm{mg})$ was calculated by multiplying the volume per receptacle $(\mathrm{mL})$ by the total number of used receptacles and by the concentration of the drug $(\mathrm{mg} /$ $\mathrm{mL}$ ). For intramammary tubes, only the concentration of the drug and total number of used receptacles were taken into calculation. Data about total volume and number of used receptacles were directly achieved from the aforementioned datasheets.

Total amount of active substance or

$$
\mathrm{ATI}=\frac{\text { combination of active substances }(\mathrm{mg}) \times 1,000}{\text { DDDA }(\mathrm{mg} / \mathrm{cow} \text {-day }) \times \text { herd-level cow-days }} \text {. }
$$

The unit of the ATI is the number of DDDA that is being used per 1,000 cows per day. The data collection period was defined as the total number of days between the starting date and the end date of the collection of receptacles by the farmer. As the total number of adult dairy cows varied very little from month to month, an average of the total number of adult dairy cows per herd (available through the DHI records) was calculated and multiplied by the total number of days within the data collection period to determine the herd-level cow-days.

Stratification of Antimicrobials. Antimicrobials were classified according to the antimicrobial drug class and route of administration and indication according to the Belgian compendium of veterinary products and the summary of the product characteristics (BCFI Vet, 2012). Intramammary antimicrobials were divided into 
intramammary injectors registered for dry-cow therapy and intramammary injectors that were registered for the intramammary treatment of (sub)clinical mastitis. All systemically injectable antimicrobials used for the therapy of various diseases are further referred to as "systemically administered antimicrobials." Intrauterine antimicrobials are further referred to as "other antimicrobials."

Stratification of Herds Based on ATI. Herds were arbitrarily divided into 3 groups of almost equal numbers based on their total ATI ranking: herds with an ATI $\leq 15$ DDDA per 1,000 cows per day were defined as low-consuming herds $(\mathrm{n}=18)$, herds with an ATI between 15 and 25 DDDA as medium-consuming herds $(\mathrm{n}=21)$, and herds with ATI $\geq 25$ DDDA as high-consuming herds $(\mathrm{n}=18)$. The average ATI in low-consuming herds was 11.92 DDDA, in mediumconsuming herds 19.89 DDDA, and in high-consuming herds 30.66 DDDA per 1,000 cow-days.

\section{Associations}

Univariable associations between ATI as continuous herd-level outcome variable and different herd-level parameters capturing udder health, milk quality and production performances (average monthly prevalence of new infections, chronic infections, and high fresh cows, IRTM, geometric mean BMSCC, geometric mean of $\mathrm{BC}$ and $\mathrm{CC}$, number of lactating cows, average herdlevel 305-d milk production, culling and calving rate and prevalence of primiparous cows) as continuous independent variables were tested using linear regression analysis (SPSS 22.0, SPSS Inc., Chicago, IL). Three similar models were fit to study the association of some study-related factors at the herd level with ATI, with (1) length of data collection period as continuous independent variable, with (2) a specifically created independent variable capturing whether a farmer indicated that also products used in young stock or by the veterinarian (or both) were collected in the garbage can $(0=$ only antimicrobials used in adult cattle collected; $1=$ also antimicrobials used in young stock or collected by veterinarians, or both), and with (3) the applied drycow strategy $[0=$ blanket dry-cow therapy $($ BDCT); 1 $=$ selective dry-cow therapy] as categorical independent variables, respectively (SPSS 22.0, SPSS Inc.). Statistical significance was set at $P \leq 0.05$ (Wald's test).

\section{RESULTS}

\section{Characterization of Herd-Level Livestock}

Thirty-two herds only housed milking cows, 13 herds also kept beef cattle, and 10 herds also farmed other animals such as veal, poultry, or pigs. Two herds housed both milking and beef cows as well as other animals such as veal, poultry, or pigs. Blanket dry-cow therapy was applied on 45 out of 57 herds.

\section{Descriptive Statistics of Herd-Level Parameters}

All information is summarized in Table 2. The average data collection period per herd was $315 \mathrm{~d}$. The average number of lactating cows was 69 . The average prevalence of new and chronic infected cows per month was 6.6 and $9.9 \%$, respectively. The average prevalence of high fresh cows was $15.9 \%$. The average IRTM during the data collection period was 9.6 treated cases per 10,000 cow-days at risk. The average of the geometric mean BMSCC, BC, and CC were 189,149 cells $/ \mathrm{mL}$, $7,443 \mathrm{IBC} / \mathrm{mL}$, and $16.5 \mathrm{cfu} / \mathrm{mL}$, respectively. The average $305-\mathrm{d}$ milk production ranged from 6,805 to $11,898 \mathrm{~kg}$. The average culling rate was 7.9 culled cows per 10,000 cow-days at risk, the average calving rate of multiparous cows was 35.7 calved cows per 10,000 cowdays at risk. The average prevalence of primiparous cows was $34.6 \%$.

\section{Antimicrobial Treatment Incidence}

Total Antimicrobial Consumption. The average total ATI was 20.78 DDDA per 1,000 cow-days, ranging from 8.68 to 41.62 DDDA (Table 3 ), with a large variation between herds (Figure 1). Penicillins were used on almost all herds $(\mathrm{n}=55)$, and third- and fourthgeneration cephalosporins were used on 48 and 51 herds out of the 57 herds, respectively.

Antimicrobial Drug Class. Fourth-generation cephalosporins had the highest ATI (4.99 DDDA per 1,000 cow-days) followed by penicillins (3.70 DDDA) and third-generation cephalosporins (2.95 DDDA). The average ATI of the critically important antimicrobials for human health; that is, third- and fourth-generation cephalosporins and fluoroquinolones (according to the OIE classification) was 8.59 DDDA, the average ATI of the not-critically-important antimicrobials combined being 12.18 DDDA (Table 3 ). With the exception of one herd, all herds used critically important antimicrobials. Large between-herd variation existed in the ATI of critically important antimicrobials (Figure 1). More than half $(58.0 \% ; 4.99 \mathrm{DDDA})$ of the total amount of critically important antimicrobials used on the participating herds include cefquinome, the only fourth-generation cephalosporin labeled for use in dairy cattle in Belgium. About one-third of the critically important antimicrobials used on the participating herds included ceftiofur, a third-generation cephalosporin with no withdrawal time for milk $(34.4 \%$; 2.58 DDDA). Of the not-critically-important antimicrobials, penicil- 
Table 2. Length of the data collection period, udder health, milk quality, and production performance of a convenience sample of 57 Flemish dairy herds from 2012 to 2013

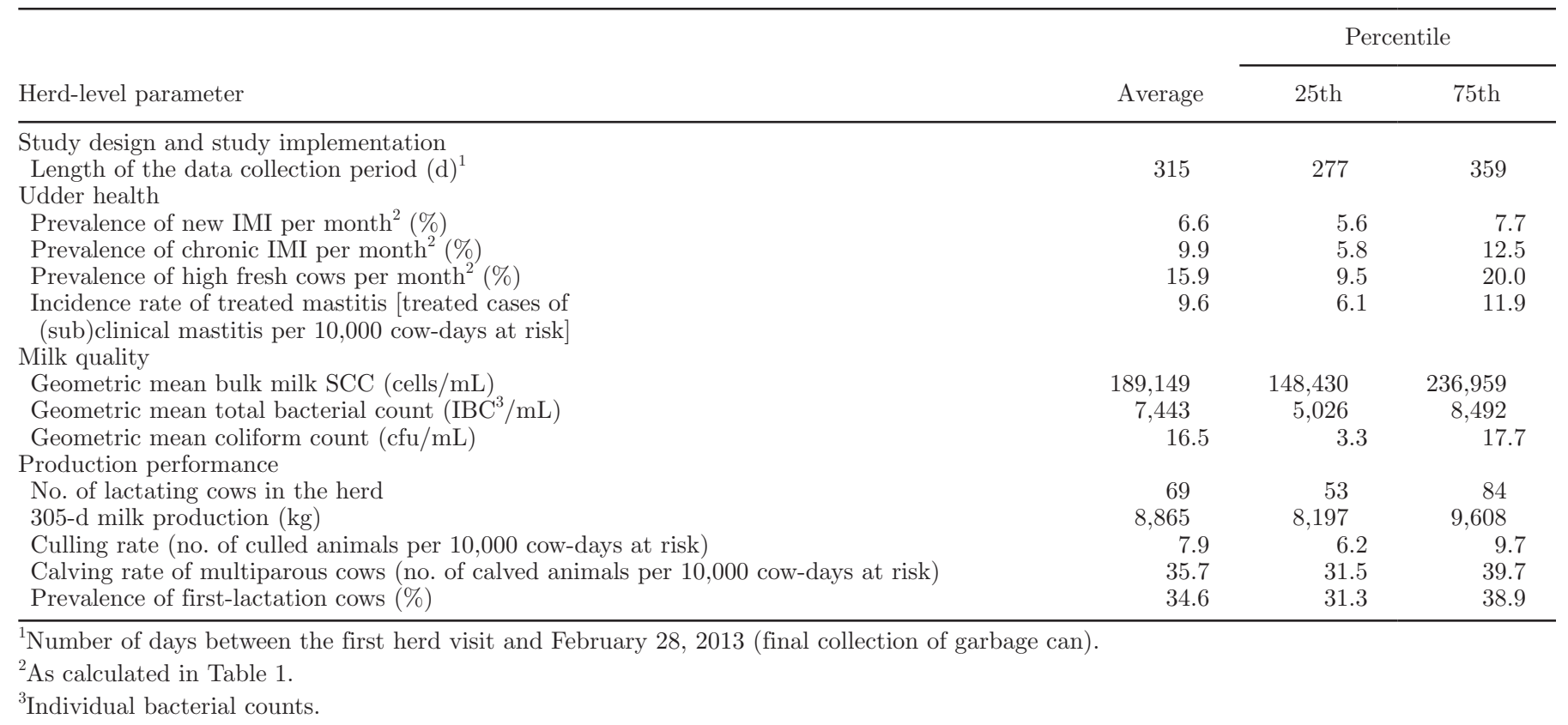

lins, first-generation cephalosporins combined with aminoglycosides and first-generation cephalosporins alone were used most $(3.70,2.24$, and 2.11 DDDA, respectively). In the low-consuming and high-consuming herds, 45.1 and $45.9 \%$, respectively, of the total AMC were critically important products (5.38 and 14.08 DDDA, respectively). About one-third (33.4\%) of the total antimicrobial consumption on medium-consuming herds involved critically important antimicrobials (6.65 DDDA).

Table 3. Antimicrobial treatment incidence (ATI; defined daily doses animal per 1,000 cow-days) of the various antimicrobial drug classes used across a convenience sample of 57 Flemish dairy herds from 2012 to 2013

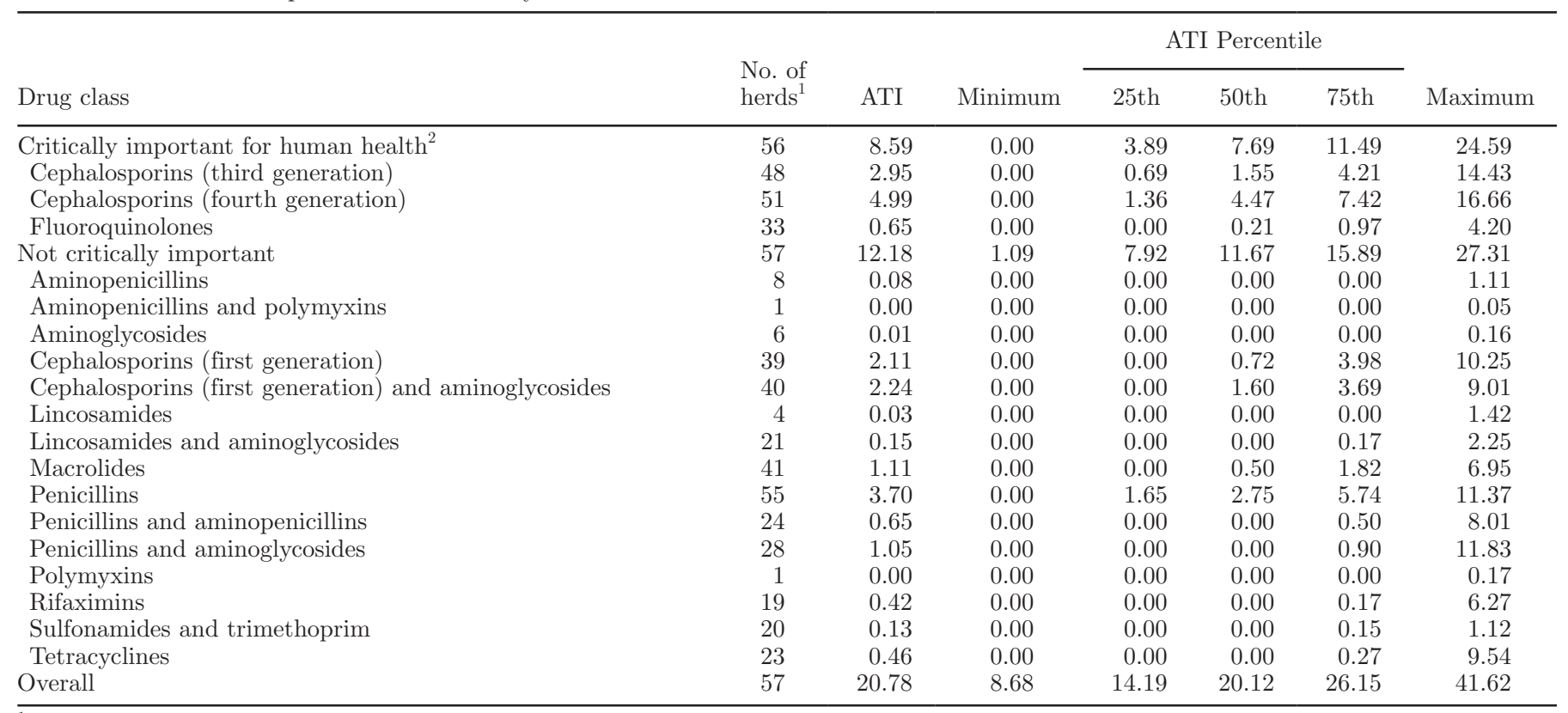

${ }^{1}$ The number of herds using the specific antimicrobial drug class.

${ }^{2}$ According to the World Health Organization, WHO. 


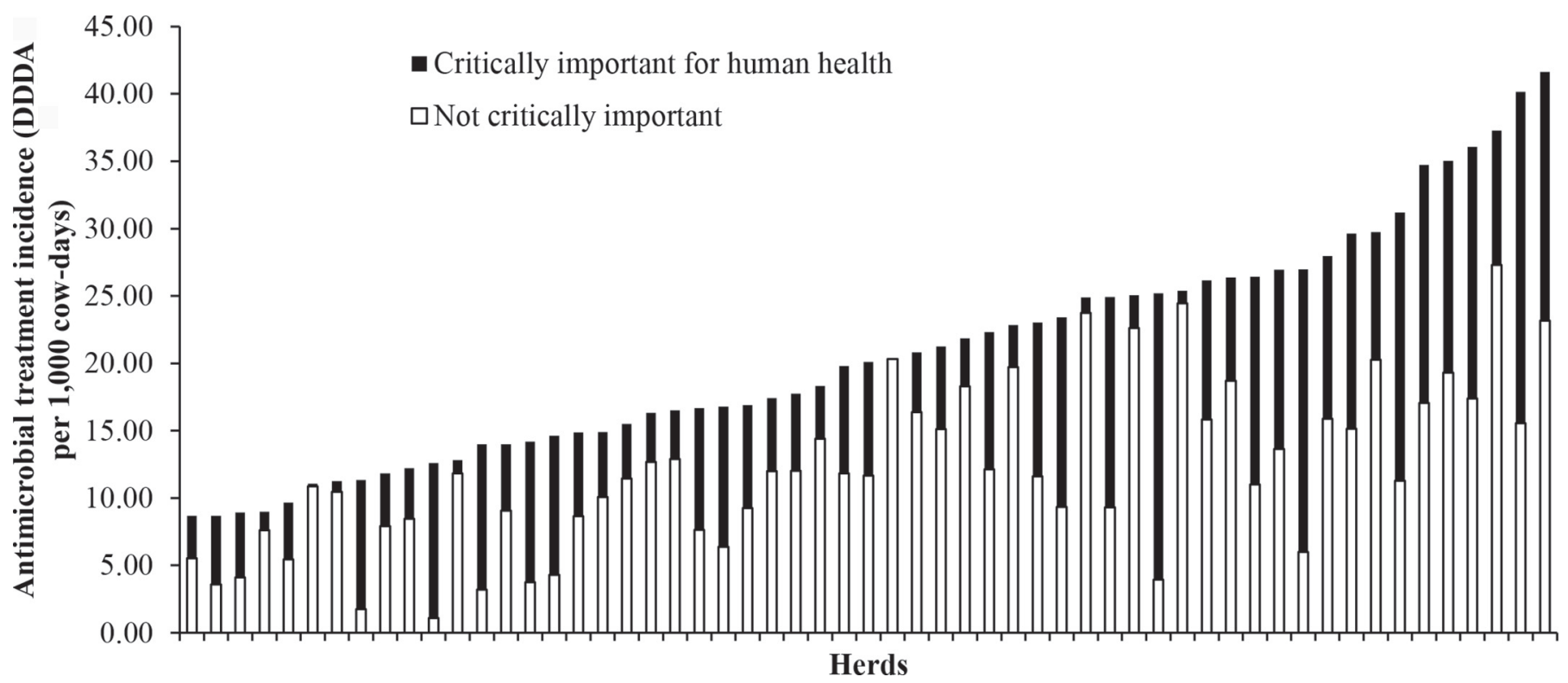

Figure 1. The herd-level antimicrobial treatment incidence [ATI; defined daily doses animal (DDDA) per 1,000 cow-days] per herd divided into critically important antimicrobials for human health and not-critically-important antimicrobials.

Route of Administration and Indication. Intramammary administered antimicrobials had the highest ATI (13.18 DDDA per 1,000 cow-days) followed by systemically administered antimicrobials (7.44 DDDA) and antimicrobials administered by other routes (e.g., intrauterine; 0.15 DDDA; Table 4).

The intramammary ATI for dry-cow therapy was 6.89 DDDA. Dry-cow injectors containing fourth-generation cephalosporins had the highest ATI (3.33 DDDA), followed by penicillins and first-generation cephalosporins (1.74 and 1.11 DDDA, respectively). Thirty-nine herds used fourth-generation cephalosporins as dry-cow treatment and 30 herds used penicillins.

The ATI was slightly lower for the intramammary treatment of (sub)clinical mastitis than for dry-cow therapy (6.30 DDDA). First-generation cephalosporins in combination with aminoglycosides had the highest ATI (2.24 DDDA) for the treatment of (sub)clinical mastitis. A large majority of the herds used fourthgeneration cephalosporins and the combination of firstgeneration cephalosporins with aminoglycosides ( $\mathrm{n}=$ 41 and $\mathrm{n}=40$, respectively) for the treatment of (sub) clinical mastitis.

Penicillins, third-generation cephalosporins, and macrolides were used systemically on 51,45 , and 41 herds, respectively. The average ATI of systemically administered antimicrobials was 7.44 DDDA, of which third-generation cephalosporins had the highest ATI (2.58 DDDA), followed by penicillins (1.95 DDDA) and macrolides (1.11 DDDA).
In the low-consuming herds, almost $44.7 \% \quad$ (5.33 DDDA) of the antimicrobials was used for dry-cow therapy, whereas $30.7 \%$ (3.66 DDDA) was used for the intramammary treatment of (sub)clinical mastitis and $24.3 \%$ (2.90 DDDA) was used systemically (Figure 2). In high-consuming herds, the majority of antimicrobials were used systemically (12.65 DDDA) or for the intramammary treatment of (sub)clinical mastitis (9.23 DDDA). In the latter group, the consumption of injectable long-acting third-generation cephalosporins with no withdrawal time for milk was relatively higher and the consumption of injectable penethamate hydriodide relatively lower compared with that of other herds. On medium-consuming herds, an almost equally high proportion of antimicrobials was used systemically for intramammary treatment of (sub)clinical mastitis and as dry-cow therapy. Other antimicrobials were used less than $1 \%$ in all 3 types of herds.

\section{Associations Between Antimicrobial Treatment Incidence and Herd-Level Parameters}

A positive association existed between IRTM and the number of herds that applied BDCT on the one hand and the low-, medium-, and high consuming herds on the other hand. Thirteen (72\%), 16 (76\%), and 16 $(89 \%)$ herds in the low-, medium- and high- consuming herds, respectively, applied BDCT (Figure 3).

As shown in Table 5, ATI was positively associated with IRTM $(P \leq 0.05$; Figure 3$)$ and negatively with 
ANTIMICROBIAL CONSUMPTION IN DAIRY HERDS IN FLANDERS

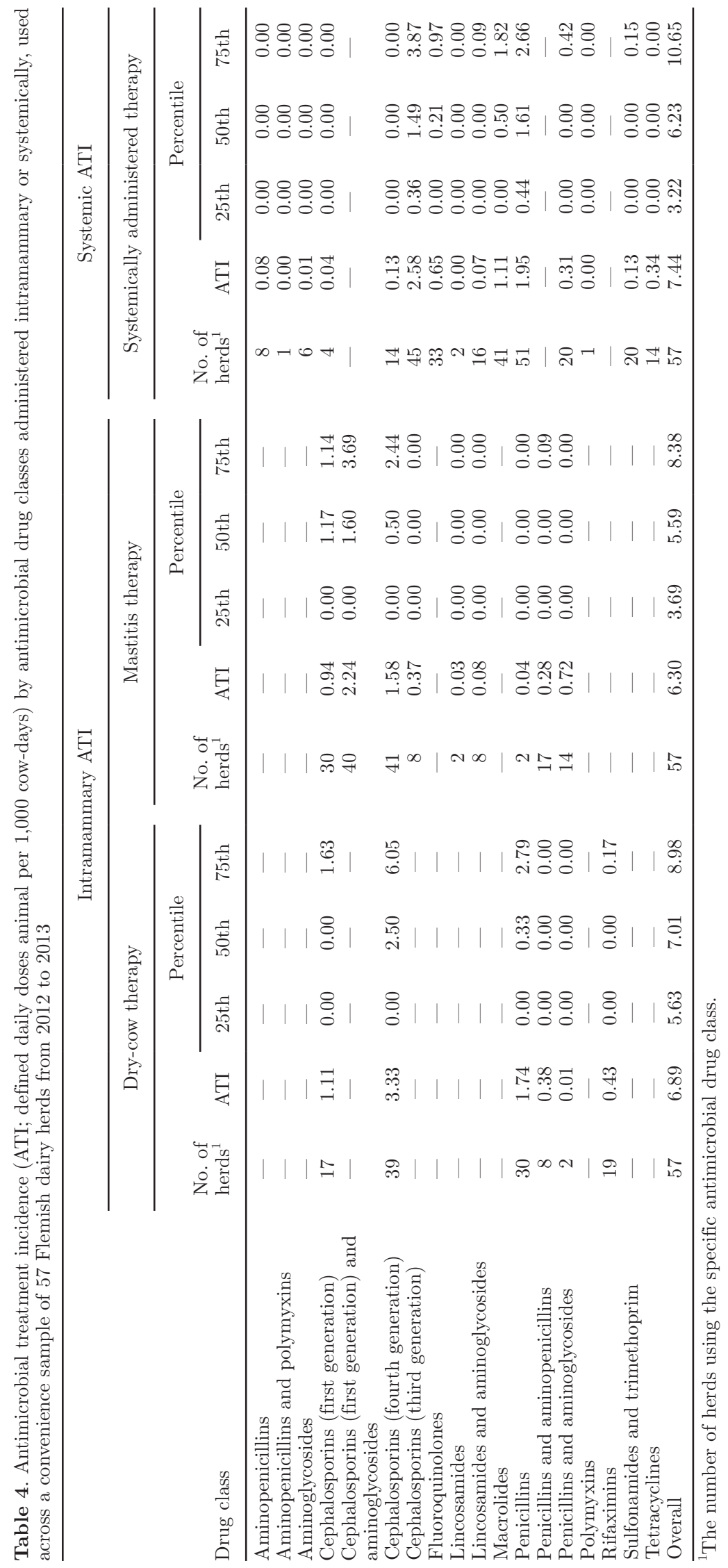




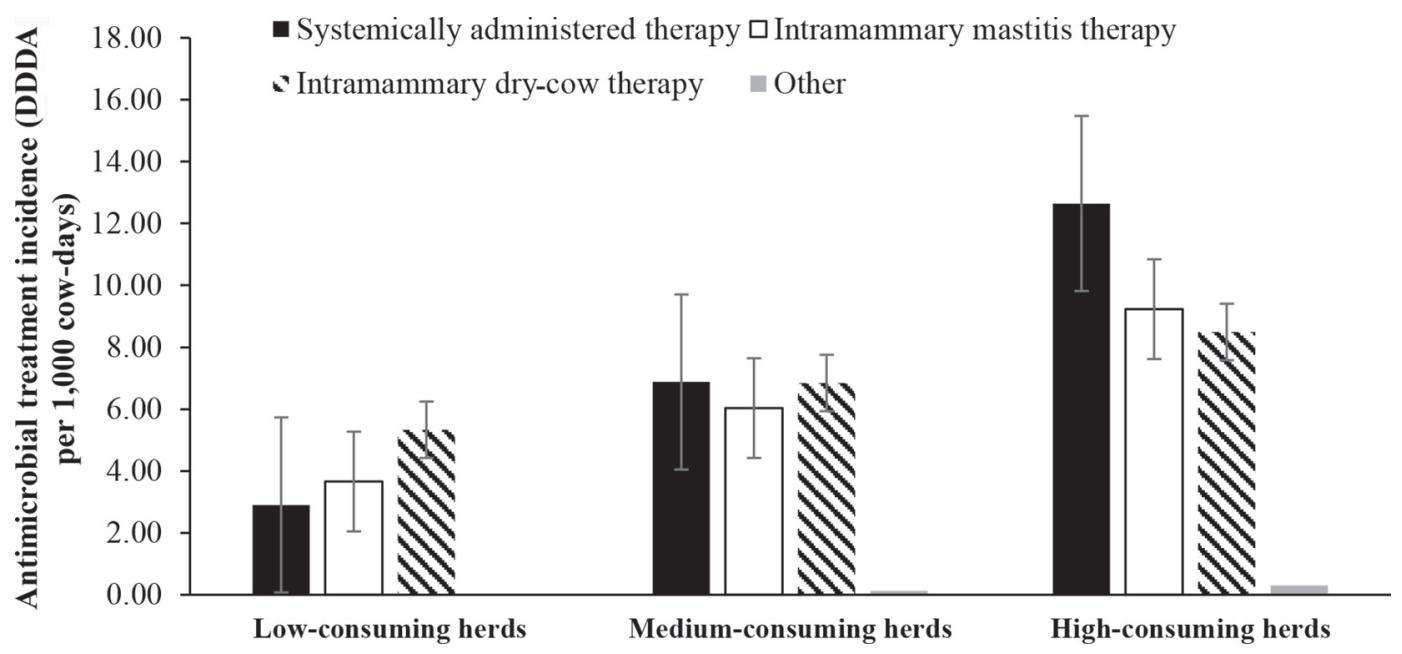

Figure 2. The herd-level average antimicrobial treatment incidence [ATI; defined daily doses animal (DDDA) per 1,000 cow-days] stratified per route of administration and so-called low-, medium-, and high-consuming herds. Low-consuming herds had an ATI $\leq 15$ DDDA per 1,000 cow-days $(\mathrm{n}=18)$; medium-consuming herds had an ATI between 15 and 25 DDDA per 1,000 cow-days $(\mathrm{n}=21)$; high-consuming herds had an ATI $\geq 25$ DDDA per 1,000 cow-days $(n=18)$. The error bars represent the standard error of the mean.

the prevalence of primiparous cows $(P \leq 0.05)$ and tended to be positively associated with the length of the data collection period per herd $(P=0.095)$. Herds that indicated as also having collected antimicrobials administered to young stock or used by veterinarians (or both) had a significantly higher ATI (although products obviously used for young stock were discarded) than the herds in which only the antimicrobials that were used for adult cows were collected $(P \leq 0.05)$. The ATI was higher on herds that applied BDCT com- pared with that in herds in which cows were selectively dried-off with dry-cow injectors $(P=0.052)$. No other associations were identified.

\section{DISCUSSION}

This is the first study set up to quantify the use of antimicrobials on dairy herds in Flanders, Belgium. Previously, only data on a wholesale level were available to understand $\mathrm{AMC}$ in the veterinary sector in

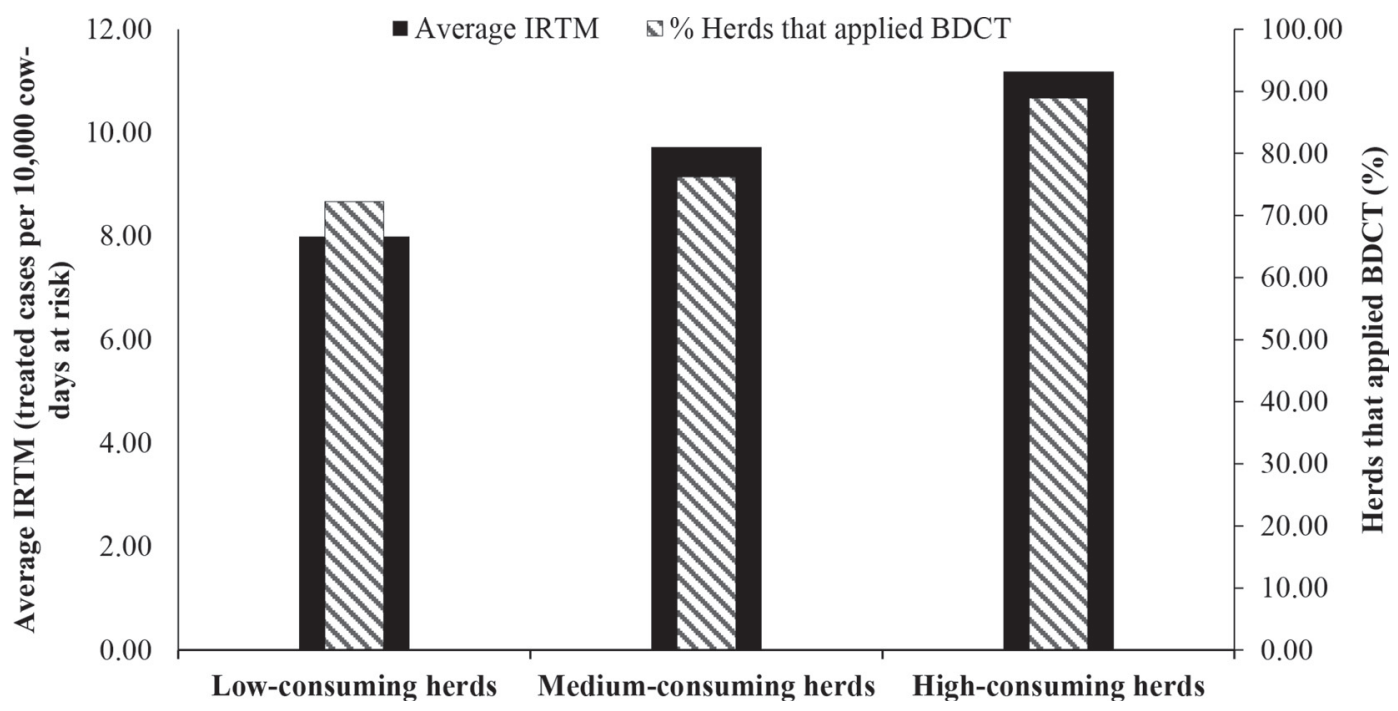

Figure 3. Percentage of herds that applied blanket dry-cow therapy (BDCT) and average incidence rate of treated mastitis (IRTM) stratified by so-called low-, medium-, and high-consuming herds. Low-consuming herds had an antimicrobial treatment incidence (ATI) $\leq 15$ defined daily doses animal (DDDA) per 1,000 cow-days $(\mathrm{n}=18)$; medium-consuming herds had an ATI between 15 and 25 DDDA per 1,000 cow-days $(\mathrm{n}=21 ; 1$ herd missing IRTM data, $\mathrm{n}=20)$; high-consuming herds had an ATI $\geq 25$ DDDA per 1,000 cow-days $(\mathrm{n}=18 ; 1$ herd missing IRTM data, $\mathrm{n}=17)$. 
Table 5. Univariable associations between the antimicrobial treatment incidence, and several parameters related to the study design and study implementation, udder health, milk quality, production performances, and applied dry-cow strategy

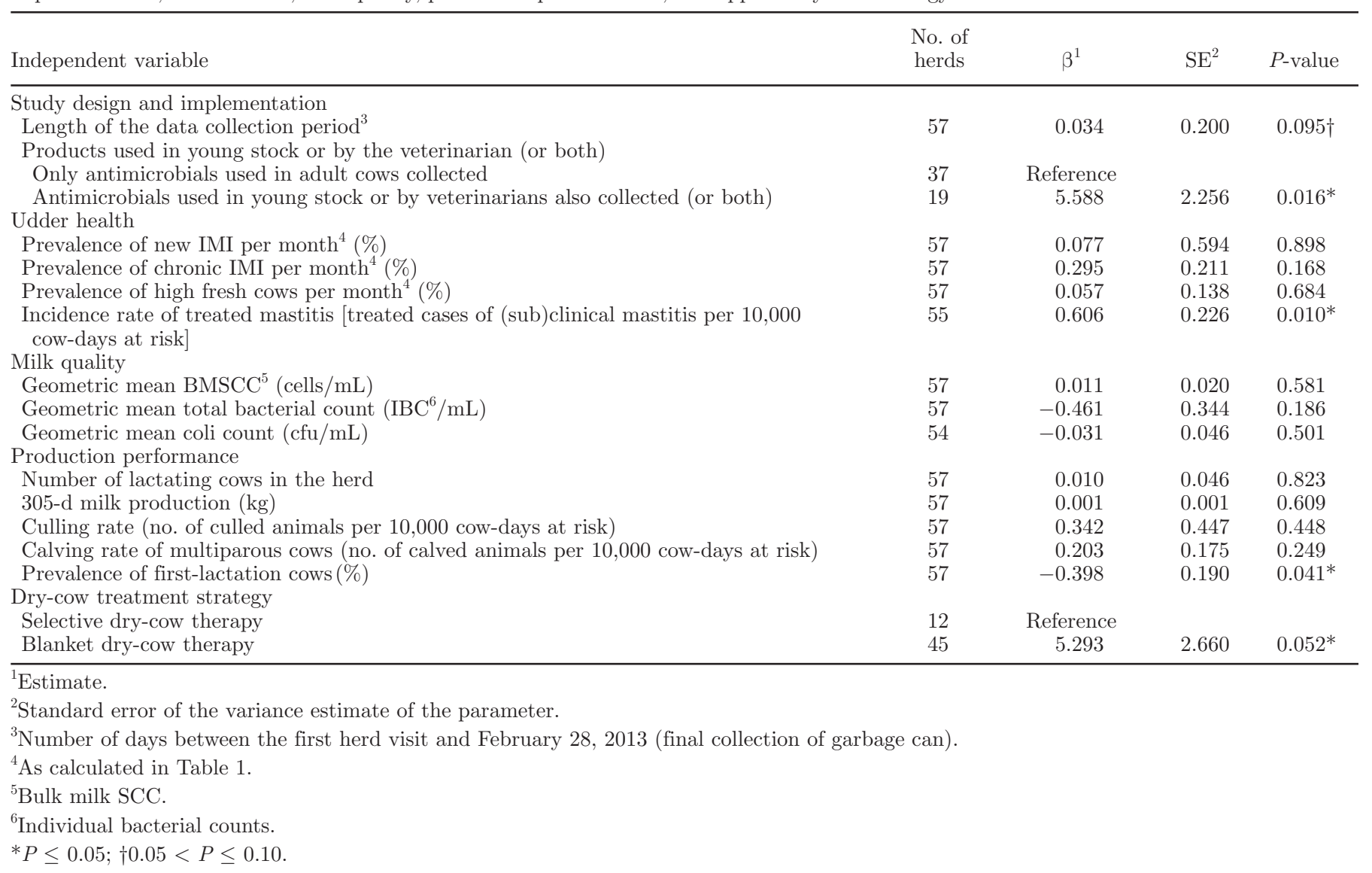

Belgium, as is still the case in many countries (Filippitzi et al., 2014; Hauck et al., 2014). Although the wholesalers' data are very informative, allowing for comparison over time and between countries, they do not allow for a precise description of the AMC per animal species or at the herd level. They do not allow us to determine between-herd variation in (compound-specific) AMC or to identify factors associated with AMC, unlike the data obtained via the garbage can method used in this study. The recorded data revealed a strong betweenherd variation in AMC and a relatively high amount of antimicrobials critically important for human health. The largest proportion of antimicrobials was used intramammary.

The garbage can method is considered one of the most reliable methods for collecting herd-level information on $\mathrm{AMC}$, despite the fact that farmers might not have disposed of all the empty drug packages in the receptacles or may not have thrown away partly used drug receptacles (Carson et al., 2008; Saini et al., 2012; Redding et al., 2014). In this study, data were collected on a convenience sample rather than on a random sample of herds, which could have introduced bias. The BMSCC, $\mathrm{BC}$, and $\mathrm{CC}$ were lower than the 222,497 cells $/ \mathrm{mL}, 12,888 \mathrm{IBC} / \mathrm{mL}$, and $19.1 \mathrm{cfu} / \mathrm{mL}$, respectively, obtained on the 275 randomly selected, nonparticipating Flemish dairy herds. The latter might suggest a potential selection bias toward the better performing dairy farms in Flanders. Antimicrobials exclusively licensed for young stock and not administered to adult cows were not taken into account, and neither were antimicrobials administered by the veterinarians. Antimicrobials used by the herd veterinarian were not permitted in the garbage cans to avoid potential overestimation of ATI in some of the herds. When a herd veterinarian administers a treatment, most of the time, only part of a specific antimicrobial package is used. Consequently, on those farms where the last dose of that particular vial would have been used by the herd veterinarian and the package disposed of in the can, the ATI would have been overestimated, especially in case of large-volume vials. Also, because in most participating herds, almost all mastitis treatments and infusions of dry-cow injectors were applied by the farmers themselves, antimicrobials administered by veterinarians likely contribute to only a very limited extent to 
the overall antimicrobial consumption on a dairy farm. Logically, in herds that nevertheless collected packages of antimicrobials administered to young stock or used by the veterinarian, ATI was higher. Although one of the herd inclusion criteria was to record not only the reason for treatment and occurrence of a disease but also the treatment duration, the interval between subsequent administrations, and the dose of the used antimicrobial, these data were often incomplete and unreliable. Therefore, antimicrobial consumption data obtained by the garbage can audits could not be compared with the AMC data received by the treatment records.

Currently, there is no internationally accepted standard for quantifying AMC in veterinary medicine (Meek et al., 1986; Dunlop et al., 1998; Timmerman et al., 2006; Carson et al., 2008; Bondt et al., 2013; Hosoi et al., 2014; Redding et al., 2014; Lanza et al., 2015), although the use of DDDA is given full priority (Jensen et al., 2004; Dewulf et al., 2013), and calculating the number of DDDA per 1,000 cow-days has been proposed by the European Medicines Agency (http://www.ema. europa.eu/ema/) as the standard for quantifying and reporting the consumption of antimicrobial agents in a European framework (Filippitzi et al., 2014). We assumed that antimicrobials were used as per directions on the label, implicating potential over- or underestimation of the ATI in case of over- or under-dosing, respectively.

Because data were collected on a convenience sample of Flemish dairy herds, care should be taken when extrapolating conclusions to the national level. Compared with the national AMC data in the Netherlands and to a study conducted in Canada (average ATI of 11.21 and 14.35 DDDA, respectively), the AMC in the participating herds of this study was rather high (Saini et al., 2012; Netherlands Veterinary Medicines Authority, 2014). However, a simple comparison is problematic because some striking differences in study design and calculation methods between those studies and ours were present, such as differences in length of data collection period, in methodology of antimicrobial data collection and in the animal (sub)population from which data were collected. As in the other studies, large variation in AMC was observed between the herds (Meek et al., 1986; Redding et al., 2014). This suggests that some farmers are able to manage their herds with limited use of antimicrobials. The management of these herds could serve as an example for herds with a higher AMC; however, when aiming for a low AMC, herd health, animal welfare, and dairy sustainability have to be taken into account as well (Netherlands Veterinary Medicines Authority, 2014).
Penicillins and cephalosporins were the most frequently used antimicrobial classes, which corresponds well to findings in other studies (Hill et al., 2009; Saini et al., 2012). The AMC of the antimicrobials critically important for human health; that is, third- and fourthgeneration cephalosporins and fluoroquinolones, varied strongly among the different herds. This suggests that it is possible to manage herds with a (very) low consumption of critically important antimicrobials. It should be mentioned that the relatively high AMC of critically important antimicrobials on this convenience sample of Flemish dairy herds, compared with the national AMC data in the Netherlands and to a study conducted in Canada (average ATI of critically important antimicrobials of 0 and 2.20 DDDA, respectively) can be partly explained by the fact that 1 of the only 2 broadspectrum dry-cow tubes that were available during the whole data collection period contained cefquinome, a fourth-generation cephalosporin. In addition, some of the (long-acting) broad-spectrum injectables with no withdrawal time for milk contained third-generation cephalosporins. No information was available on the reasons behind the use of these formulations as the use of these type of treatments does not need to be recorded by either the veterinarian or the farmer if administered at least 2 mo before the culling date. As distribution to the udder tissue is low (as can be derived from the absence of withdrawal time for milk), we believe these products were typically used for fertility problems, respiratory disorders, and claw diseases. A reduction in the use of critically important antimicrobials for human health could be obtained by using alternatives for drycow injector and systemic (long-acting) antimicrobials without withdrawal time for milk, which contain thirdand fourth-generation cephalosporins.

The observation that the majority of antimicrobials were for intramammary use corresponds well with the findings of some other studies (Pol and Ruegg, 2007; Hill et al., 2009) but is in contrast to the findings of a Canadian study, in which most antimicrobials were used systemically (Saini et al., 2012). The consumption of intrauterine antimicrobials was low compared with that in the study of Meek et al. (1986) and is probably an underestimation as we believe some packages did not end up in the garbage cans.

Not all herds that applied selective dry-cow therapy were in the group of low-consuming herds, and that group also included herds that applied BDCT. In the low-consuming herds, most antimicrobials were being used in dry-cow therapy, whereas in the high-consuming herds, most antimicrobials were administered systemically or as intramammary mastitis therapy, suggesting that a difference in strategy toward a reduction in AMC 
is needed between these types of herds. Reduction of the AMC in the low-consuming herds could be achieved by opting for conditional selective dry-cow therapy. We hypothesize that high-consuming herds should first optimize general udder health and treatment approaches of mastitis as this will likely result in a lower IRTM, and consequently in a lower consumption of intramammary antimicrobials used for mastitis therapy. In addition, a reduction of systemically used antimicrobials could be achieved by improving general animal health management so that less systemic critically important (long-acting) broad-spectrum antimicrobials with no milk withdrawal time are needed. Because of the longacting activity of the latter products, one injection counts for several DDDA, resulting in a considerable contribution of these products to the total ATI. This change will need a substantial mind shift from both dairy producers and veterinarians.

Part of the herd-level variation in the total ATI could be explained by differences in the IRTM, dry-cow strategy, and prevalence of primiparous cows. The latter 2 are, together with the calving rate of multiparous cows, parameters with an influence on AMC of dry-cow antimicrobials. The association between AMC and the applied dry-cow strategy reinforces the observations of Scherpenzeel et al. (2014), in which selectively drying off cows with antimicrobials based on their SCC at the last DHI recording before drying off resulted in a lower AMC despite an increased incidence of clinical mastitis in the next lactation. The negative association between ATI and the prevalence of primiparous cows corresponds well with the fact that younger cows have a lower incidence of (sub)clinical mastitis (Ali et al., 2014; Verbeke et al., 2014) and do not receive dry-cow antimicrobials. The AMC was not, however, affected by the calving rate of multiparous cows, which was calculated here as a proxy for the calving interval. Although high-producing cows are more susceptible to mastitis (Gröhn et al., 1995) and herds with high milk production have a higher incidence of clinical mastitis (Schukken et al., 1990), no association could be found between 305-d production and AMC in this study, indicating that high production results can be obtained without high AMC. In fact, only a limited number of the investigated parameters were found to be associated with AMC. The quantification of AMC tended to be influenced by the length of the data collection period. Farmers did not throw partly used drug vials in the garbage can during the data collection period, potentially resulting in an underestimation of the true AMC during the data collection period. Our findings suggest that this risk of underestimation is higher with a shorter data collection period. Of course, in addition to the parameters included in this study, variation in
AMC between herds could be explained by other factors such as treatment decisions, therapy compliance, and udder health and (health) management in general.

\section{CONCLUSIONS}

The average ATI on a convenience sample of Flemish dairy herds was high, with a large between-herd variation for the overall $\mathrm{AMC}$, and for the critically important antimicrobials in particular. The majority of antimicrobials used were intramammary. Antimicrobials used in dry-cow therapy accounted for the largest proportion of the ATI in low-consuming herds, whereas in high-consuming herds, the proportion of systemic antimicrobials and intramammary mastitis antimicrobials were used most. Therefore, a reduction of ATI requires a different approach in low-consuming than in high-consuming herds. The incidence rate of treated mastitis was positively associated with ATI. Herds that applied BDCT tended to have higher ATI than herds where cows were only selectively dried off with long-acting antimicrobials. The ATI decreased with an increasing prevalence of primiparous cows. Parameters related to the study design and study implementation could influence the quantification of AMC, and should be taken into account when setting up new studies and when interpreting AMC results.

\section{ACKNOWLEDGMENTS}

All farmers who cooperated are gratefully acknowledged. We especially thank all M-team (UGent) colleagues for helping with the herd visits. Thanks must go to the Milk Control Centre Flanders, the Farmers Union (Boerenbond), Milk Control Centre Flanders (Lier, Belgium), the Farmers Union (Boerenbond, Leuven, Belgium), The Milk Quality Label (IKM-QFL, Brussels, Belgium), and the Belgian Confederation of the Dairy Industry (BCZ, Leuven, Belgium) for partially financing this study.

\section{REFERENCES}

Ali, T., A. Rahman, M. S. Qureshi, M. T. Hussain, M. S. Khan, S. Uddin, M. Iqbal, and B. Han. 2014. Effect of management practices and animal age on incidence of mastitis in Nili Ravi buffaloes. Trop. Anim. Health Prod. 46:1279-1285.

BCFI Vet (Het Belgisch Centrum voor Farmacotherapeutische Informatie). 2012. Gecommentarieerd geneesmiddelenrepertorium voor diergeneeskundig gebruik. http://www.bcfi-vet.be/.

Bondt, N., V. F. Jensen, L. F. Puister-Jansen, and I. M. van Geijlswijk. 2013. Comparing antimicrobial exposure based on sales data. Prev. Vet. Med. 108:10-20.

Bos, M. E., F. J. Taverne, I. M. van Geijlswijk, J. W. Mouton, D. J. Mevius, and D. J. Heederik. 2013. Consumption of antimicrobials in pigs, veal calves, and broilers in the Netherlands: Quantita- 
tive results of nationwide collection of data in 2011. PLoS ONE 8:e77525.

Callens, B., D. Persoons, D. Maes, M. Laanen, M. Postma, F. Boyen, F. Haesebrouck, P. Butaye, B. Catry, and J. Dewulf. 2012. Prophylactic and metaphylactic antimicrobial use in Belgian fattening pig herds. Prev. Vet. Med. 106:53-62.

Carson, C. A., R. Reid-Smith, R. J. Irwin, W. S. Martin, and S. A. McEwen. 2008. Antimicrobial use on 24 beef farms in Ontario. Can. J. Vet. Res. 72:109-118.

Chantziaras, I., F. Boyen, B. Callens, and J. Dewulf. 2014. Correlation between veterinary antimicrobial use and antimicrobial resistance in food-producing animals: A report on seven countries. J. Antimicrob. Chemother. 69:827-834.

DeVincent, S. J., and C. Viola. 2006. Introduction to animal antimicrobial use data collection in the United States: Methodological options. Prev. Vet. Med. 73:105-109.

Dewulf, J., G. Moulin, B. Catry, C. Chauvin, C. Greko, D. J. Heederik, E. Jacobsen, I. M. Van Geijlswijk, S. A. McEwen, C. Müntener, and I. Litleskare. 2013. Revised ESVAC reflection paper on collecting data on consumption of antimicrobial agents per animal species, on technical units of measurement and indicators for reporting consumption of antimicrobial agents in animals. London, UK.

Dunlop, R. H., S. A. McEwen, A. H. Meek, W. D. Black, R. C. Clarke, and R. M. Friendship. 1998. Individual and group antimicrobial usage rates on 34 farrow-to-finish swine farms in Ontario, Canada. Prev. Vet. Med. 34:247-264

Federal Public Service Economy. Small and Medium Enterprises, SelfEmployed, and Energy. 2011. Landbouwtelling 2010. Accessed Jul. 20 2012. http://statbel.fgov.be/nl/binaries/3.1.3.6.1.Landbouw\%20 definitief\%20T\%202010\%2005_tcm325-118744.xls.

Filippitzi, M. E., B. Callens, B. Pardon, D. Persoons, and J. Dewulf. 2014. Antimicrobial use in pigs, broilers and veal calves in Belgium. Vlaams Diergen. Skund. Tijds. 83:215-224.

Grave, K., C. Greko, L. Nilsson, K. Odensvik, T. Mørk, and M. Rønning. 1999. The usage of veterinary antibacterial drugs for mastitis in cattle in Norway and Sweden during 1990-1997. Prev. Vet. Med. $42: 45-55$

Gröhn, Y. T., S. W. Eicker, and J. A. Hertl. 1995. The association between previous 305-day milk yield and disease in New York State dairy cows. J. Dairy Sci. 78:1693-1702.

Hauck, R., A. Romer, I. Reimer, A. Bender, C. Haas, T. Heberer, and J. Wallmann. 2014. Analysis of the distribution of veterinary antimicrobial products to veterinarians in Germany in 2011 and 2012. Berl. Munch. Tierarztl. Wochenschr. 127:359-365.

Hill, A. E., A. L. Green, B. A. Wagner, and D. A. Dargatz. 2009. Relationship between herd size and annual prevalence of and primary antimicrobial treatments for common diseases on dairy operations in the United States. Prev. Vet. Med. 88:264-277.

Hosoi, Y., T. Asai, R. Koike, M. Tsuyuki, and K. Sugiura. 2014. Sales of veterinary antimicrobial agents for therapeutic use in food-producing animal species in Japan between 2005 and 2010. Rev. Sci. Tech. 33:1007-1015.

Jensen, V. F., E. Jacobsen, and F. Bager. 2004. Veterinary antimicrobial-usage statistics based on standardized measures of dosage. Prev. Vet. Med. 64:201-215.

Lanza, G., F. Faccini, M. Valdonio, N. Arrigoni, P. Pattarini, B. Grilli, E. Cabrini, M. Boccellino, and M. Delledonne. 2015. Consumption and methods of use of antibacterial agents in the breeding of dairy cattle in the province of Piacenza. Large Anim. Rev. 21:51-60.

Marshall, B. M., and S. B. Levy. 2011. Food animals and antimicrobials: Impacts on human health. Clin. Microbiol. Rev. 24:718-733.

Meek, A. H., S. W. Martin, J. B. Stone, I. McMillan, J. B. Britney, and D. G. Grieve. 1986. The relationship among current management-Systems, production, disease and drug usage on Ontario dairy farms. Can. J. Vet. Res. 50:7-14

Morley, P. S., M. D. Apley, T. E. Besser, D. P. Burney, P. J. FedorkaCray, M. G. Papich, J. L. Traub-Dargatz, and J. S. Weese. 2005.
Antimicrobial drug use in veterinary medicine. J. Vet. Intern. Med. 19:617-629.

Netherlands Veterinary Medicines Authority. 2014. Usage of antibiotics in livestock in the Netherlands in 2014. Accessed Sep. 2015. http://www.autoriteitdiergeneesmiddelen.nl/Userfiles/pdf/SDarapporten/def-sda-rapport-ab-2014-engels-v2-aangepast-102015incl-erratum.pdf.

Oliver, S. P., and S. E. Murinda. 2012. Antimicrobial resistance of mastitis pathogens. Vet. Clin. North Am. Food Anim. Pract. $28: 165-185$

Pardon, B., B. Catry, J. Dewulf, D. Persoons, M. Hostens, K. De Bleecker, and P. Deprez. 2012. Prospective study on quantitative and qualitative antimicrobial and anti-inflammatory drug use in white veal calves. J. Antimicrob. Chemother. 67:1027-1038.

Persoons, D., J. Dewulf, A. Smet, L. Herman, M. Heyndrickx, A. Martel, B. Catry, P. Butaye, and F. Haesebrouck. 2012. Antimicrobial use in Belgian broiler production. Prev. Vet. Med. 105:320-325.

Phillips, I., M. Casewell, T. Cox, B. De Groot, C. Friis, R. Jones, C. Nightingale, R. Preston, and J. Waddell. 2004. Does the use of antibiotics in food animals pose a risk to human health? A critical review of published data. J. Antimicrob. Chemother. 53:28-52.

Pol, M., and P. L. Ruegg. 2007. Treatment practices and quantification of antimicrobial drug usage in conventional and organic dairy farms in Wisconsin. J. Dairy Sci. 90:249-261.

Postma, M., M. Sjolund, L. Collineau, S. Losken, K. D. C. Stark, J. Dewulf, and M. Consortium. 2015. Assigning defined daily doses animal: A European multi-country experience for antimicrobial products authorized for usage in pigs. J. Antimicrob. Chemother. 70:294-302.

Redding, L. E., F. Cubas-Delgado, M. D. Sammel, G. Smith, D. T. Galligan, M. Z. Levy, and S. Hennessy. 2014. Comparison of two methods for collecting antibiotic use data on small dairy farms. Prev. Vet. Med. 114:213-222.

Saini, V., J. T. McClure, D. Leger, S. Dufour, A. G. Sheldon, D. T. Scholl, and H. W. Barkema. 2012. Antimicrobial use on Canadian dairy farms. J. Dairy Sci. 95:1209-1221.

Sawant, A. A., L. M. Sordillo, and B. M. Jayarao. 2005. A survey on antibiotic usage in dairy herds in Pennsylvania. J. Dairy Sci. 88:2991-2999.

Scherpenzeel, C. G. M., I. E. M. den Uijl, G. van Schaik, R. Riekerink, and T. Lam. 2014. Evaluation of the use of dry cow antibiotics in low somatic count cows. J. Dairy Sci. 97:3606-3614.

Schukken, Y. H., F. J. Grommers, D. Van de Geer, H. N. Erb, and A. Brand. 1990. Risk factors for clinical mastitis in herds with a low bulk milk somatic cell count. 1. Data and risk factors for all cases. J. Dairy Sci. 73:3463-3471.

Schwarz, S., C. Kehrenberg, and T. R. Walsh. 2001. Use of antimicrobial agents in veterinary medicine and food animal production. Int. J. Antimicrob. Agents 17:431-437.

Timmerman, T., J. Dewulf, B. Catry, B. Feyen, G. Opsomer, A. de Kruif, and D. Maes. 2006. Quantification and evaluation of antimicrobial drug use in group treatments for fattening pigs in Belgium. Prev. Vet. Med. 74:251-263.

van den Bogaard, A. E., and E. E. Stobberingh. 2000. Epidemiology of resistance to antibiotics - Links between animals and humans. Int. J. Antimicrob. Agents 14:327-335.

Verbeke, J., S. Piepers, K. Supre, and S. De Vliegher. 2014. Pathogenspecific incidence rate of clinical mastitis in Flemish dairy herds, severity, and association with herd hygiene. J. Dairy Sci. 97:69266934

Vieira, A. R., S. M. Pires, H. Houe, and H.-D. Emborg. 2011. Trends in slaughter pig production and antimicrobial consumption in Danish slaughter pig herds, 2002-2008. Epidemiol. Infect. 139(Special Issue 10):1601-1609.

Wray, C., and J. C. Gnanou. 2000. Antibiotic resistance monitoring in bacteria of animal origin: Analysis of national monitoring programmes. Int. J. Antimicrob. Agents 14:291-294. 